\title{
Quality-of-life assessment in children and adolescents with asthma
}

\author{
C. Rutishauser*, S.M. Sawyer*+, G. Bowes*
}

\begin{abstract}
Quality-of-life assessment in children and adolescents with asthma. C. Rutishauser, S.M. Sawyer, G. Bowes. CERS Journals Ltd 1998.

ABSTRACT: Health-related quality of life has become an essential part of health outcome measurement in chronic disorders. However, it is only recently that health professionals have focused on quality-of-life assessment in children and adolescents. Several generic, as well as the asthma-specific quality-of-life instruments specifically designed for use in children and adolescents are reviewed in this article with particular regard to the conceptual and methodological features of the measures and their applicability in clinical studies. The recently published Child Health Questionnaire is a useful generic instrument to comprehensively assess quality of life, in particular when comparing young people with different chronic disorders. The Pediatric Asthma Quality-of-life Questionnaire has shown responsiveness to change over time, but it lacks age-specificity with regard to psychosocial issues and comprehensiveness of quality-of-life assessment. In contrast, the Childhood Asthma Questionnaire provides three different versions for different target ages. However, its generic part is not reflective of the respondent's health status. The other asthma-specific instruments have major conceptual deficiencies when used as a single measure for quality-of-life assessment. In the absence of a single ideal instrument, the use of batteries of qualityof-life instruments is therefore recommended and further research is required to identify the impact that age and developmental status have on quality-of-life assessment. Eur Respir J 1998; 12: 486-494.
\end{abstract}

*Centre for Adolescent Health and +Dept of Thoracic Medicine, Royal Children's Hospital, Melbourne, Victoria, Australia.

Correspondence: C. Rutishauser

Centre for Adolescent Health

2 Gatehouse Street

Parkville

Victoria 3056

Australia

Fax: 61393456502

Keywords: Asthma

children and adolescents

outcome assessment

quality of life

Received: June 161997

Accepted after revision January 131998

$\mathrm{CR}$ is supported in part by the following noncommercial Swiss institutions: Lung Association of Zurich, Ciba-Geigy-Jubilee-Foundation, Theodor and Ida HerzogEgli Foundation.
Quality-of-life assessment is increasingly recognized as an important health outcome measure in asthma [1-3]. The measurement of health-related quality of life is based on the growing recognition during the last two decades that healthcare should not only focus on the patient's survival or quantity of life, but also on the quality of the extended life [4]. In patients with chronic disorders, which are not curable but only treatable, quality-of-life assessment may be even more relevant, as achievement of the best possible quality of life becomes the major goal of patient management [5].

Asthma is the most common chronic disease in children and adolescents [6]. Although a range of highly effective asthma medication is available for symptomatic control, current treatments have failed to significantly reduce morbidity or mortality $[7,8]$, particularly in adolescents $[9$, 10]. Until recently, mortality rates and physiological measures of lung function were the cornerstones of outcome assessment in asthma. Physiological measures have greatly contributed to a better understanding of the pathophysiology of asthma and will continue to be important diagnostically and in evaluating the response to treatment. However, they fail to provide a better understanding of the gap between the availability of effective medical treatment and the fact that a reduction in morbidity and mortality has not been achieved.

In contrast to traditional asthma outcome research which has focused mainly on physiological measures, quality-oflife instruments aim to measure the impact of a disease upon the patient's daily life [11]. Using this broad patient- centered approach, quality-of-life instruments have the potential to contribute to a better understanding of the impact of asthma on the patient's daily functioning, as well as to evaluate asthma managements and their impact on the patient's daily life [12]. There is evidence that quality of life is not (or only weakly) correlated with lung function parameters [13-15]. This does not reduce the value of these assessments, but rather highlights the possibility of combining physiological measures with quality-of-life assessment.

In the assessment of quality of life in children and adolescents, age-specific characteristics need to be considered. This article describes the conceptual and methodological requirements of quality-of-life instruments for children and adolescents. Instruments available for children and adolescents with asthma are then reviewed within a framework that aims to describe the conceptual basis of each instrument while highlighting the methodological strengths and weaknesses.

\section{Conceptual issues}

\section{Definition of quality of life}

In clinical medicine, quality of life reflects the World Health Organization's definition of health as "the state of complete physical, mental, and social well-being and not merely the absence of disease or infirmity" [16]. Quality-of-life measurement is therefore a multidimensional 
assessment, as it usually includes physical functioning and somatic sensation, as well as social and emotional functioning and well-being [17].

Several definitions of health-related quality of life have been suggested. One of the well known definitions proposed by SCHPPER et al. [11] is: "Quality of life in clinical medicine represents the functional effect of an illness and its consequent therapy upon a patient, as perceived by the patient" [11]. While the absence of a unique definition for quality of life has been criticized [18, 19], the value of quality-of-life assessment is not necessarily diminished. The lack of a unique definition highlights the importance of explicitly defining the term whenever developing or using a quality-of-life instrument [19]. As long as this is the case, objective methods can be used to measure the subjective perception of health in clinical trials [20].

To some extent, quality of life is a substitute for terms such as health status or functional status, as these also measure the impact an illness has on the patient's functioning in daily life. However, whereas some investigators use the terms quality of life, health status and functional status interchangeably [21], others have suggested that the concept of quality of life should additionally include an individual rating of the value that different dimensions of quality of life have to the target population or the target individual [2]. As a result, different concepts have been chosen in the development of quality-of-life instruments. Further clarification and consensus is necessary to determine whether health status, functional status and quality of life can be used synonymously and whether individual item-value rating has the potential to contribute to the accuracy of quality-of-life assessment.

The term quality of life may not have a unique meaning, as an individual's personality, personal values, experience of illness and approach to life will influence the meaning of health-related quality of life for that individual [22]. As a consequence, comparisons of quality of life between individuals may be misleading. In addition, healthrelated quality of life is also influenced by non-healthrelated quality-of-life issues such as family structure and financial status [23]. This has to be taken into consideration when comparing quality of life between different subpopulations.

\section{Generic versus disease-specific instruments}

A principle decision in assessing quality of life is whether the investigator uses a generic or a disease-specific quality-of-life instrument. In recent years a large number of disease-specific measures have been developed in fields such as oncology, rheumatology, and geriatrics [24]. The decision to use a generic or a disease-specific instrument should be primarily based on the objectives of the study $[21,22]$.

Generic instruments (i.e. measures that are neither disease- nor domain-specific) are particularly useful when comparing quality of life of subpopulations with different diseases, or when comparing a population with a particular disease to a healthy control group $[22,25]$. In contrast, disease-specific instruments focus on the domains most relevant to a particular disorder and its treatment. A major advantage of disease-specific measures is their potential to be more responsive to change over time [1,21]. Disease- specific instruments are therefore particularly recommended in clinical trials that focus on measuring change of quality of life due to an intervention. Disease-specific measures only contain issues relevant to the target population and can therefore enquire about highly specific details. They are usually shorter than generic instruments, which enhances the practicability of disease-specific instruments in children and adolescents. However, to date both generic and disease-specific measures have significant limitations. The use of batteries of both generic and disease-specific instruments might be considered, depending on the practicability of this more comprehensive approach [26].

\section{Quality of life in individual patient management}

The majority of quality-of-life instruments have only been used in clinical research. Some patient-generated instruments are available and are designed for individual patient assessment $[27,28]$. However, these patient-generated measures do not specifically address issues relevant to asthma. While they have the potential to reflect the patient's burden of illness in general, they do not provide any information on how asthma affects the person's daily functioning. The utility of quality-of-life instruments for individual patient management needs to be evaluated further.

\section{Parent versus child completion}

Whose perception should be assessed? In children the majority of quality-of-life measures are designed for parent-completion [29]. Parents' answers are a proxy response for their children's daily functioning. This is in contrast to the expectation that quality-of-life instruments should focus on the individual's subjective perception [30].

There is evidence that children's perceptions differ from their parents' judgement [31, 32]. Proxy assessment of health status may be valuable in younger children, especially if it is combined with a child's self-reported information. However, proxy assessments are not sufficiently able to take into account the subjective nature of qualityof-life measurement. This would support the need to make a conceptual distinction between health status and quality of life. Health status may be proxy assessed, whereas quality of life is based on the individual's personal perception and should always be self-reported. Furthermore, proxy assessments can be strongly influenced by how much the subject's health condition is a burden to the caregivers themselves [33]. Although it is important to recognize the parental burden of a child's illness, care needs to be taken to ensure that the parental burden is measured separately to the quality of life of the child [34].

An adolescent's perception of their health-related quality of life may be influenced by their cognitive development [35], as well as by peer group perceptions and a myriad of influences that result from the achievement of adolescent developmental tasks such as body self-integrity and personal identity, autonomy and independence, and educational and vocational goals. The personal views of adolescents will therefore significantly enhance a health professional's understanding of how young people experience the impact of asthma on their daily functioning. For 
these reasons proxy assessments of quality of life should be firmly avoided in adolescents. A recently published study [36] measuring quality of life in children and adolescents with asthma confirmed this by concluding that in adolescents over the age of 11 yrs "parents can provide little if any information beyond that obtained through questioning the child".

\section{Age considerations}

Little is known about the minimal age required for selfreported quality-of-life measurement. The cognitive capabilities of the target age-group have to be considered when developing an instrument as well as when choosing one for a particular study. A minimum age of 9 or 10 yrs has been recommended for self-assessment of subjective concepts such as behaviour and self-esteem [37]. There is some evidence that even younger children are able to answer simply worded questions about emotional issues, particularly if the response options are represented by pictograms (in children, usually "Smiley" faces) [38]. Using pictured questions to test anxiety, high reliability is reported for children as young as 4 yrs [39]. The effect of illustrations on the validity of responses was examined by LARSON et al. [40] using the Darmourth COOP Charts. They concluded that pictures do not appear to affect res-ponses. However, with particular regard to disease-speci-fic quality-of-life instruments, even using pictograms still raises the major concern of whether younger children have the cognitive capabilities to reliably answer questions specifically asking about the impact of a disease on their daily functioning (e.g. to differentiate whether their emotional feelings are a result of asthma or another issue).

With regard to the administration of quality-of-life questionnaires, well-trained interviewers can prevent the inappropriate assistance of parents, which may influence the child's perception [41]. In adolescents, the use of computer-administered instruments may be advantageous. Not only do adolescents enjoy using this technology (which may improve participation rates), but less time is required to answer questions if branched formatting is used [42]. In addition, computer-administered instruments may enhance the rate of honest self-report when asking about personal and potentially embarrassing issues such as adherence to medication, risk-taking behaviour and sexuality.

Another age-related problem is the choice of time frame to be used in considering questions. In instruments for adults, questions are frequently asked in relation to the previous 2 or 4 weeks. In children and adolescents, time frames of 1-4 weeks have been used [14, 43]. The limited cognitive capabilities of children raises the question of whether a 10 yr old child can reliably answer quality-oflife-related questions framed over the past month. It is well known that even adults have difficulty remembering episodes of illness [44]. Further investigation is required to clarify the most appropriate time frame for questions in children and adolescents.

\section{Methodological issues}

\section{Validity}

An instrument is valid if it measures what it is supposed to measure. Unfortunately, there is no gold standard for validation of quality of life. Due to the lack of a gold standard, construct validity is an important method of validation $[5,45]$. Construct validity means testing a number of hypotheses of how the quality-of-life instrument should behave in comparison with other measures. This is a timeconsuming and ongoing process, and although data of validity are published for many quality-of-life instruments, one should consider carefully how and for what purpose the instrument has been validated. Often only content validity is reported, which is a judgement by experts that the instrument contains all the relevant domains. With regard to quality-of-life research in children and adolescents the choice of instrument should be based on the purpose, age and characteristics of the target population the instrument has been validated for. Instruments designed and validated for adults have frequently been used to assess quality of life in children and adolescents because of the lack of available measures for younger age groups [46, 47]. The lack of validity of this approach is obvious given the differences in cognitive and psychosocial development in children, adolescents and adults.

\section{Reliability and responsiveness}

Internal consistency is an important measure of an instrument's reliability, while test-retest reliability provides evidence of how accurately the instrument measures something in a reproducible fashion. Reliability is therefore a measure of the instrument's stability [45]. Additionally, responsiveness to change over time is considered to be an important measure, as disease-specific instruments are often used in clinical intervention studies where the goal is to measure whether a particular intervention has the potential to improve quality of life. A major problem in measuring an instrument's responsiveness is data interpretation $[22,48]$. A change of quality-of-life scores may be statistically significant, but this does not necessarily mean that it is relevant for the patient. Although some framework has been provided to assess an instrument's minimal clinically important difference [49] (also referred to as "sensitivity to change" $[22,50])$, this has only been determined for a minority of instruments.

\section{Instruments}

\section{Generic measures}

A number of generic health-status instruments (often referred to as quality-of-life instruments) are available for use in children and adolescents. A detailed description of these measures exceeds the purpose of this article and has been the subject of a recent excellent review by LANDGRAF and AвETZ [37]. Nevertheless, to illustrate some of the important conceptual issues, a selection of generic measures are briefly described. The selection has been made solely to illustrate these conceptual issues.

Several generic instruments for the assessment of children's and adolescents' health status are designed for proxy assessment by parents (e.g. National Health Interview Survey, Functional Status II-R, RAND Health Insurance Experiment [51-53]). As already outlined, preference should be given for self-assessment of health-related quality of life, particularly in adolescents. 
The recently developed Child Health Questionnaire (CHQ) [43] recognizes the different developmental stages of children and adolescents by providing a version for parent completion (age range 5-17 yrs), as well as a self-report version for adolescents aged 10-17 yrs. The parent completed version contains 50 items, the self-completed version 87 items. The CHQ includes a broad range of dimensions focusing on physical, mental and social functioning, as well as components of family impact and risk behaviour. The questionnaire's psychometric properties have been tested in a wide range of different chronic diseases.

A number of generic instruments designed for selfreport in children and adolescents are too long for clinical studies. For example, the Adolescent Child Health and Illness Profile for adolescents aged 11-17 yrs contains 153 items $[54,55]$ which will hinder full participation by adolescents. The self-reported version of the CHQ contains 87 items which may be too long for some clinical studies. A shorter self-report version of the CHQ is desirable. In contrast, the COOP adolescent charts [56] contain only six items, each focusing on one health status domain. In addition to brevity it has user-friendly illustrations. Although the COOP adolescent charts have adequate testretest reliability, the validity of this instrument has not been investigated thoroughly. Its conceptual framework makes it more appropriate as a screening instrument than a comprehensive measure of quality of life.

The 16-dimensional (16D) and the 17-dimensional health-related measure (17D) are two other recently published generic instruments [57,58]. The $16 \mathrm{D}$ (16 items) is designed for adolescents aged 12-15 yrs, the 17D (17 items) is suitable for children aged 8-11 yrs. Both instruments contain one item for each dimension. Both of these instruments fulfill three important requirements of quality-of-life assessment in children and adolescents: 1) they are designed for self-completion by children and adolescents themselves; 2) they provide two conceptually similar, but age-adjusted instruments for different age groups; 3 ) they are both brief and require only 5-10 $\mathrm{min}$ to complete. However, like some other generic instruments [37, 54], these include dimensions such as "hearing" and "eating" which are of little relevance in asthma. The disadvantage of the inclusion of domains with low relevance in people with asthma is that they reduce the instrument's responsiveness, especially if a total score is calculated.
Also, both questionnaires are written in Finnish, and English versions are currently not available.

Overall, the Child Health Questionnaire appears to be a promising generic instrument for comprehensive qualityof-life assessment in children and adolescents, particularly when investigating different populations with different diseases or comparing a target population with a healthy control group.

\section{Asthma-specific measures}

Disease-specific instruments have been increasingly used in clinical studies of asthma. This section reviews the currently available asthma-specific quality-of-life instruments for children and adolescents (table 1).

Pediatric Asthma Quality-of-life Questionnaire. In 1992 JuNPER et al. [59] published the (McMaster) Asthma Quality-of-life Questionnaire which has been used success-fully in clinical trials in adults with asthma. The recently published Pediatric Asthma Quality-of-life Questionnaire (PAQLQ) [14] is a 23-item measure for the age range 717 yrs. The PAQLQ is primarily designed for evaluative purposes (i.e. responsive to change over time), but it is also suitable for discriminative objectives (i.e. the ability to differentiate between those people with better and those with worse quality of life). It uses a seven-point response scale. The PAQLQ has good construct validity, responsiveness to change over time and test-retest reliability. Further validation is, however, necessary as there is only limited validity data in different age groups because of the small sample size in the questionnaire's previous validation.

A major problem with the PAQLQ is that a single version covers the age range $7-17$ yrs. While such a wide age range may have the advantage of allowing broad comparisons between different age groups, age-related differences in cognitive, social and emotional development are not considered. Quality of life is thought to be a multidimensional concept that ideally covers all domains relevant to a particular target population. However, the PAQLQ focuses mainly on the patients' perceptions of symptoms (10 out of 23 items) and emotional function (eight out of 23 items), domains important to all age groups. Limitation in

Table 1. - Asthma-specific quality-of-life instruments for children and adolescents

\begin{tabular}{|c|c|c|c|c|c|}
\hline Instrument & $\begin{array}{l}\text { Age range } \\
\text { yrs }\end{array}$ & $\begin{array}{c}\text { Items } \\
\mathrm{n}\end{array}$ & Respondent & Domains & $\begin{array}{c}\text { Mode of } \\
\text { administration }\end{array}$ \\
\hline $\begin{array}{l}\text { Pediatric Asthma Quality of } \\
\text { Life Questionnaire }\end{array}$ & $7-17$ & 23 & Youth & $\begin{array}{l}\text { Symptoms, limitations in } \\
\text { activities, emotional function }\end{array}$ & $\begin{array}{l}\text { Self-/interview- } \\
\text { administered }\end{array}$ \\
\hline \multicolumn{6}{|l|}{ Childhood Asthma Questionnaire } \\
\hline Form A & $4-7$ & 14 & Child* & QoL, distress & Self-administered \\
\hline Form B & $8-11$ & $22 / 19 * *$ & Child & $\begin{array}{l}\text { Active QoL, passive QoL, } \\
\text { distress, severity }\end{array}$ & Self-administered \\
\hline Form $\mathrm{C}$ & $12-16$ & $31 / 24 * *$ & Youth & $\begin{array}{l}\text { Active QoL, teenage QoL, } \\
\text { distress, severity, reactivity }\end{array}$ & Self-administered \\
\hline $\begin{array}{l}\text { Life Activities Questionnaire for } \\
\text { Childhood Asthma }\end{array}$ & $5-17$ & 71 & Child, youth & $\begin{array}{l}\text { Physical activities, work, } \\
\text { outdoor activities, emotional } \\
\text { behaviour, home care, eating } \\
\text { and drinking, miscellaneous }\end{array}$ & Self-administered \\
\hline $\begin{array}{l}\text { Asthma Symptom and Disability } \\
\text { Questionnaire }\end{array}$ & $5-14$ & 17 & Parent & $\begin{array}{l}\text { Disability, nocturnal symptoms, } \\
\text { daytime symptoms }\end{array}$ & Self-administered \\
\hline
\end{tabular}

*: with assistance of interviewer/parent; **: second figure describes the Australian version. QoL: quality of living. 
physical activity is only covered by five items. Psychosocial issues are of particular importance for adolescents, yet the PAQLQ does not include a social domain. Items concentrating on the impact that asthma may have on school attendance, vocational goals, exposure to peer group smoking or concerns about taking medication are also absent. The PAQLQ's main focus on symptoms and emotional well-being may contribute to its excellent responsiveness, as these domains are likely to respond faster and more significantly to therapeutic interventions than a social domain. However, the lack of inclusion of a social domain as well as other psychosocial issues threatens the validity of this instrument to comprehensively measure quality of life.

Another concern is in regard to the domain "activity limitations". This domain is appreciative of different preferences at different ages by providing individualized items. Respondents can choose their physical activities of relevance from a list containing 35 options including totally different activities, such as sleeping, walking, dancing or playing football. However, there is evidence that individualized items make statistical analysis and interpretation of results difficult [60].

Childhood Asthma Questionnaires (CAQ). This instrument $[61,62]$ has different forms for three different age groups; 4-7 yrs (Form A); 8-11 yrs (Form B); and 12-16 yrs (Form C). The original British and a more recent Australian version are available. The number of items ranges 14-30, depending mainly on the target age of each questionnaire and whether the British or the Australian version is used (the latter is shorter). Each item contains two questions; the first asks about the frequency of an issue (activity, symptoms etc.) and the second focuses on how much the respondent perceives the issue to be a problem. Response options range 2-4 options in Form $A$ and 4-5 options in Form C.

The strength of the CAQ is the availability of different questionnaires for different ages. This concept allows questions to focus on age-relevant issues formulated in age-appropriate language. For example, Form $\mathrm{C}$ for adolescents contains items asking about school attendance, smoking, concerns about taking asthma medication, peer group activities, etc. Also helpful is the use of "Smiley" faces to visualize response options.

The major concern with regard to the CAQ is the theoretical construct on which the instrument is based, having both generic and disease-specific components. The goal of the generic section is to provide comparison data for daily activities between healthy and asthmatic children and adolescents. Unfortunately, the questions in the generic component are not set in the context of health. Asthma may influence the choice of activities, such as swimming or attending parties, but the failure to emphasize that these questions should be answered with regard to limitations due to the respondent's health status means that the an-swers may depend more on personal preference than on asthma. This is supported by the fact that in the validation process, no significant differences were found between healthy and asthmatic children for the generic section of the CAQ, suggesting that either the majority of asthmatic children had only mild asthma or that even in the context of a true difference, the formula- tion of the generic items may not have discriminative value. More importantly, the absence of specification is highly likely to reduce the in-strument's responsiveness in clinical intervention studies which is the primary purpose of the CAQ [61]. Finally, the instrument includes items (such as reading books) that are unlikely to be affected by health status changes due to medical intervention which will further limit the instrument's responsiveness. It is therefore not surprising that in an intervention study investigating the effect of salmeterol in adolescents with severe asthma, the CAQ's distress score and the qualityof-living scores did not change significantly during the 8 week trial while the self-reported asthma severity score improved due to treatment with salmeterol [63].

The three questionnaires of both versions have adequate internal consistency and good test-retest reliability. However, the CAQ has not yet been sufficiently validated to be used confidently in clinical trials. Although the CAQ was designed primarily for use in the clinical evaluation of new treatments for paediatric asthma [61], the validation was mainly performed in a community-based sample. As a result, no clinical data of asthma severity are available from the participants in the validation studies to correlate asthma severity and quality of life, as part of the assessment of construct validity. Although there is evidence that health-related quality of life is only weakly to moderately correlated with some clinical parameters of asthma severity, it is important to assess the subjects' asthma severity to test the correlation with the CAQ's quality-of-life scores, as well as to provide an important descriptive measure of the target population's characteristics. Comparison of the CAQ with other measures of quality of life is also desirable.

Life Activities Questionnaire for Childhood Asthma (LAQ). This 71-item instrument [64] is a multidimensional tool for the age range 5-17 yrs which assesses activity limitations in five different categories: physical activities, work activities, outdoor activities, emotions and emotional behaviours and home care. Responses are given on a fivepoint scale. Content validity was achieved by asking 92 children and adolescents aged 5-17 yrs (and the parents of the younger children) to identify the most relevant activities in which restrictions due to asthma were experienced. The instrument showed a high internal consistency and good test-retest reliability. No data is available for the instrument's responsiveness.

The difference between the LAQ and other quality-oflife measures is that the LAQ focuses particularly on activities, even in the "emotions and emotional behaviours" domain (laughing, stress, shouting, yelling). CREER et al. [64] who developed the LAQ suggest that the LAQ can be used as a component in a battery of measures of morbidity to assess quality of life in children with asthma, although the length of the LAQ may preclude this.

Asthma Symptom and Disability Questionnaire (ASDQ). Sometimes listed as a quality-of-life instrument, this 17item questionnaire is parent-completed with the aim to quantify the perceived asthma symptoms and disabilities of children and adolescents aged 5-14 yrs [65]. A fivepoint response scale is given to answer each question. 
There are three separately scored components: disability, nocturnal symptoms and daytime symptoms. The ASDQ has good content validity, but further validity data are not available.

It could be argued that the advantage of the ASDQ lies in its simplicity, as the disability domain represents the impact of asthma on the patient's overall functioning, and symptoms are scored separately. The disadvantage of the ASDQ is its failure to include aspects of emotional distress due to asthma and that it is a parental proxy assessment of the child's health-related quality of life.

\section{Measures related to quality of life}

A number of instruments are not quality-of-life measures, as they do not measure all the major aspects of health-related quality of life, but focus on specific dimensions of quality of life or issues related to quality of life in children and adolescents with asthma. Instruments conceptually related to asthma-specific quality-of-life measures are briefly described here to give an understanding of the relationship with quality of life and to discuss their utility in quality-of-life assessment (table 2).

Functional Asthma Severity Scale (FASS). The authors of the FASS suggest a differentiation between functional and physiological severity (assessed by lung function) [66]. It is a brief six-item instrument designed for parent-completion. It measures severity of asthma symptoms as well as limitations in the child's activities which may be summed to a total score to assess functional severity. The FASS showed good validity and reliability and can be used to separately assess functional asthma severity or as part of a battery of instruments to measure health-related quality of life. However, as proxy assessment by parents is inappropriate, the FASS would benefit from modification (and revalidation) for self-completion in adolescents.

Asthma Problem Behaviour Checklist (APBC). The APBC is a structured interview instrument to be administered to either the child (aged 5-15 yrs) or his/her parents [67]. The APBC has two goals: firstly, identification of behavioural problems of children before and during an asthma attack; and secondly, identification of the consequences of asthma that affect not only the child, but also his or her family. The 72 items cover five major areas: general infor- mation including characteristics of a child's asthma; identification of behaviours important in the prevention of attacks, such as compliance with medication; attack-related behaviours; behavioural consequences that result from asthma; and socioeconomic factors. The APBC has good testretest reliability and good content validity in regard to detecting asthma-related problem behaviours. Although elsewhere the APBC is listed as an asthma-specific quality-oflife measure [2], it only partially contains quality-of-life related issues and therefore is not a true quality-of-life instrument.

Schlösser Self-Efficacy Scale (SES). This 38-item instrument was designed and validated for adolescents aged 1018 yrs [68]. It aims to assess a young person's perceived self-efficacy in the process of decision making around asthma management and the estimation of personal abilities to deal with asthma. The three subscales of the SES are medical treatment, environment and problem solving. It can be argued that the degree of self-efficacy expectation is positively correlated with perceived quality of life and may be a valuable component of a quality-of-life assessment. However, Schlösser and HaverMANS [68] rep-orted that some modification of the SES is required due to difficulties in younger adolescents aged 10-14 yrs.

Pediatric Asthma Caregiver's Quality-of-life Questionnaire (PACQLQ) and the Impact-on-Family Scale (IFS). Childhood asthma affects not only the child's quality of life, but also impacts upon parental well-being, which can then influence the child's quality of life. TowNSEND et al. [69] showed that "caregivers of children with asthma are limited in their own normal daily activities and also experience anxieties and emotional stresses as a result of their children's asthma". Based on this study, JuNIPER et al. [34] developed the PACQLQ. This instrument contains 13 items assessing the two domains "emotional function" and "activities". A high level of correlation has been demonstrated with the IFS [70]. The authors of the PACQLQ suggested that problems associated with caring for a child with asthma may not be asthma-specific, but are a general phenomenon of looking after a sick child. For this reason, preference may be given to the generic IFS, as this instrument also allows comparisons with subpopulations with other diseases.

Table 2. - Measures related to quality of life for children and adolescents with asthma

\begin{tabular}{|c|c|c|c|c|c|}
\hline Instrument & $\begin{array}{c}\text { Age range } \\
\text { yrs }\end{array}$ & $\begin{array}{c}\text { Items } \\
\mathrm{n}\end{array}$ & Respondent & Domains & $\begin{array}{c}\text { Mode of } \\
\text { administration }\end{array}$ \\
\hline Functional Asthma Severity Scale & School age* & 6 & Parent & Symptoms, physical activities & Self-administered \\
\hline $\begin{array}{l}\text { Asthma Problem Behaviour } \\
\text { Checklist }\end{array}$ & $5-15$ & 72 & $\begin{array}{l}\text { Youth, } \\
\text { Parent }\end{array}$ & $\begin{array}{l}\text { General, prevention of attacks, } \\
\text { attack-related behaviours, } \\
\text { behavioural consequences } \\
\text { resulting from asthma, } \\
\text { socioeconomic factors }\end{array}$ & $\begin{array}{l}\text { Structured interview/ } \\
\text { self-administered }\end{array}$ \\
\hline Schlösser Self-Efficacy Scale & $10-18$ & 22 & Youth & $\begin{array}{l}\text { Medical treatment, environment, } \\
\text { problem-solving skills }\end{array}$ & Self-administered \\
\hline $\begin{array}{l}\text { Pediatric Asthma Caregiver's } \\
\text { Quality of Life Questionnaire }\end{array}$ & Parent** & 13 & Parent & $\begin{array}{l}\text { Overall quality of life, emotional } \\
\text { function, activity limitation }\end{array}$ & Self-administered \\
\hline Impact-on-Family Scale & Family*** & 24 & Parent & $\begin{array}{l}\text { Financial, social/familial, } \\
\text { personal strain, mastery }\end{array}$ & Self-administered \\
\hline
\end{tabular}

*: age range not fully defined (approximately 7-17 yrs); **: the caregiver's quality of life (usually parent) given the child has asthma and is aged $7-17 \mathrm{yrs}$; ***: the family's quality of life of chronically ill children. 


\section{Conclusion}

Quality-of-life measurement is increasingly recognized as a cornerstone of integrated health-outcome assessment and for the evaluation of clinical interventions in specific diseases such as asthma. Both generic and asthma-specific instruments have been developed for children and adolescents over the last few years.

Depending on the research question, generic instruments are required when comparing an asthmatic population with another disease group or a healthy control group. In intervention studies focusing exclusively on asthma, preference should be given to asthma-specific instruments.

Currently, few asthma-specific quality-of-life instruments are available. The major strength of the Paediatric Asthma Quality-of-life Questionnaire [14] is its responsiveness to change over time. Its weakness is that it lacks age specificity with regard to psychosocial issues. In contrast, the strength of the Childhood Asthma Questionnaire [61] is the use of three different questionnaires for different target ages. Its weakness is that due to conceptual deficiencies the generic part of the CAQ is not reflective of the respondent's health status. This reduces its responsiveness and its validity. The other two asthma-specific instruments, the Asthma Symptom and Disability Questionnaire [65] and the Life Activities Questionnaire for Childhood Asthma [64] have not been validated thoroughly and have major conceptual deficiencies in appropriately assessing quality of life when used as a single instrument. They may, however, be of value in combination with other measures.

The conceptual and methodological differences between the Paediatric Asthma Quality-of-life Questionnaire and the Childhood Asthma Questionnaire highlight an important dilemma in instrument design. The inclusion of psychosocial items is essential when measuring quality of life. However, a majority of these items are likely to reduce a measure's responsiveness to change. For example, an adolescent's relationship to peer groups or the fear of having asthma attacks will not improve as rapidly as his or her capacity to perform in physical activities following optimization of asthma treatment. The inclusion of a broad range of psychosocial domains (resulting in a highly comprehensive instrument) will therefore reduce an instrument's responsiveness. One solution would be to omit domains, such as the social domain, with the sole goal of developing a highly responsive measure. However, this would result in a simple symptom checklist with denial of any impact of asthma on other domains within quality of life. We believe that the inclusion of psychosocial items is particularly important for adolescents and adults, but every item must be explicitly related to the respondent's health status. The challenge for further quality-of-life research is to strike a balance between responsiveness and comprehensiveness of quality-of-life measures.

It is accepted that quality-of-life assessment in children and adolescents with asthma should be age-appropriate by consideration of the impact that maturation has on activities and disease as children pass through adolescence into adult life. Research that identifies the impact that age and developmental status have on instrument development in quality-of-life assessment is a priority. Quality-of-life assessment in adolescents cannot necessarily be assessed with the same measures as used in younger children or adults. This limits comparison between these age groups. How- ever, quality-of-life assessment, being a subjective perception of the individual, should be as age-specific as possible to ensure that the issues most relevant to the individual are covered. To facilitate comparison between different ages, a selection of core items relevant to every age may be valuable.

Self-completion of quality-of-life instruments is a basic requirement of quality-of-life assessment. Proxy assessments of a child's health status may at times be valuable, but should be avoided if quality of life is to be measured, being a subjective perception. Further research is necessary to identify the minimal age for reliable self-completion of disease specific quality-of-life instruments.

In the absence of a single ideal instrument, the use of batteries of quality-of-life instruments is recommended in community-based as well as clinical studies. This will help to clarify the strengths of each instrument, as well as provide more evidence about the instrument's validity and clinical usefulness.

Health-outcome research, as it relates to quality-of-life instruments, is an evolving field, not just conceptually, but also methodologically, and in particular with regard to children and adolescents where cognitive and developmental issues need to be sensitively accommodated. A critical attitude is recommended when reading quality-of-life studies, especially when conclusions are made without using a validated quality-of-life instrument [71, 72].

Quality-of-life assessment in children and adolescents with asthma is an important tool to use if we are to reduce the current gap in understanding that exists between health professionals' knowledge of the physiological correlates of asthma and the individual burden of experiencing asthma. The development of generic and disease-specific quality-of-life instruments is an important first step. However, a more informed understanding of the impact of age and development on instrument design is required if we are to comprehensively measure the full impact of asthma on young people.

\section{References}

1. McSweeny AJ, Creer TL. Health-related quality-of-life assessment in medical care. Dis Mon 1995; 41: 3-71.

2. Richards JM, Hemstreet MP. Measures of life quality, role performance, and functional status in asthma research. Am J Respir Crit Care Med 1994; 149: S31-S39.

3. Jones PW. Quality of life measurement in asthma. Eur Respir J 1995; 8: 885-887.

4. Spitzer WO. State of science 1986: quality of life and functional status as target variables for research. J Chron Dis 1987; 40: 465-471.

5. Guyatt GH, Bombardier C, Tugwell PX. Measuring disease-specific quality of life in clinical trials. Can Med Assoc J 1986; 134: 889-895.

6. Taylor WR, Newacheck PW. Impact of childhood asthma on health. Pediatrics 1992; 90: 657-662.

7. Altemeier WA. Children with asthma: we can do better. Pediatric Ann 1996; 25: 120-125.

8. Mellis CM, Peat JK, Bauman AE, Woolcock AJ. The cost of asthma in New South Wales. Med J Aust 1991; 155: 522-528.

9. Forero R, Bauman A, Young L, Larkin P. Asthma prevalence and management in Australian adolescents: results from three community surveys. J Adolesc Health 1992; 13: 707-712. 
10. de Benedictis FM, Canny GJ, Levison H. The progressive nature of childhood asthma. Lung 1990; Suppl.: 278-285.

11. Schipper H, Clinch J, Powell V. Definitions and conceptual issues. In: Spilker B, ed. Quality of Life Assessments in Clinical Trials. New York, Raven Press, 1990; pp. 1135 .

12. Health and Public Policy Committee, American College of Physicians. Comprehensive functional assessment for elderly patients. Ann Intern Med 1988; 109: 70-72

13. Juniper EF, Guyatt GH, Ferrie PJ, Griffith LE. Measuring quality of life in asthma. Am Rev Respir Dis 1993; 147: 832-838.

14. Juniper EF, Guyatt GH, Feeny DH, Ferrie PJ, Griffith LE, Townsend M. Measuring quality of life in children with asthma. Qual Life Res 1996; 5: 35-46.

15. Marks GB, Dunn SM, Woolcock AJ. A scale for the measurement of quality of life in adults with asthma. J Clin Epidemiol 1992; 45: 461-472.

16. World Health Organization. Constitution of the World Health Organization. Geneva, WHO, 1947.

17. Schumacher M, Olschewski M, Schulgen G. Assessment of quality of life in clinical trials. Stat Med 1991; 10: 1915-1930.

18. Bergner M. Quality of life, health status, and clinical research. Med Care 1989; 27: S148-S156.

19. Gill TM, Feinstein AR. A critical appraisal of the quality of quality-of-life measurements. JAMA 1994; 272: 619626.

20. Wassertheil-Smoller S. Biostatistics and Epidemiology. New York, Springer-Verlag, 1995; pp. 147-155.

21. Guyatt GH, Feeny DH, Patrick DL. Measuring healthrelated quality of life. Ann Intern Med 1993; 118: 622-629.

22. Testa MA, Simonson DC. Assessment of quality-of-life outcomes. N Engl J Med 1996; 334: 835-840.

23. Spilker B, Revicki DA. Taxonomy of quality of life. In: Spilker B, ed. Quality of Life and Pharmacoeconomics in Clinical Trials. Philadelphia, Lippincott-Raven Publishers, 1996; pp. 25-31.

24. Berzon RA, Donnelly MA, Simpson RL, Simeon GP, Tilson HH. Quality of life bibliography and indexes: 1994 update. Qual Life Res 1995; 4: 547-569.

25. Patrick DL, Deyo RA. Generic and disease-specific measures in assessing health status and quality of life. Med Care 1989; 27: S217-S232.

26. Bender BG. Measurement of quality of life in pediatric asthma clinical trials. Ann Allergy Asthma Immunol 1996; 77: 438-447.

27. Hickey AM, Bury G, O'Boyle CA, Bradley F, O'Kelly FD, Shannon W. A new short form individual quality of life measure (SEIQoL-DW): application in a cohort of individuals with HIV/AIDS. BMJ 1996; 313: 29-33.

28. Paterson C. Measuring outcomes in primary care: a patient generated measure, MYMOP, compared with the SF36 health survey. BMJ 1996; 312: 1016-1020.

29. Bowling A. Measuring disease. Buckingham, Open University Press, $1995 ;$ p. 278.

30. Slevin ML, Plant H, Lynch D, Drinkwater J, Gregory WM. Who should measure quality of life, the doctor or the patient? Br J Cancer 1988; 57: 109-112.

31. Herjanic B, Reich W. Development of a structured psychiatric interview for children: agreement between child and parent on individual symptoms. J Abnorm Child Psychol 1982; 10: 307-324.

32. Reich W, Herjanic B, Welner Z, Gandhy PR. Development of a structured psychiatric interview for children: agreement on diagnosis comparing child and parent interviews. J Abnorm Chld Psychol 1982; 10: 325-336.
33. Rothman ML, Hendrick SC, Blucroft KA, Hickman DH, Rubenstein LZ. The validity of proxy-generated scores as measures of patient health status. Med Care 1991; 29: $115-124$.

34. Juniper EF, Guyatt GH, Feeny DH, Ferrie PJ, Griffith LE, Townsend M. Measuring quality of life in the parents of children with asthma. Qual Life Res 1996; 5: 27-34.

35. Rosenbaum PL, Saigal S. Measuring health-related quality of life in pediatric populations: conceptual issues. In: Spilker B, ed. Quality of Life and Pharmacoeconomics in Clinical Trials. Philadelphia, Lippincott-Raven Publishers, 1996; pp. 785-791.

36. Guyatt GH, Juniper EF, Griffith LE, Feeny DH, Ferrie PJ. Children and adult perceptions of childhood asthma. Pediatrics 1997; 99: 165-168.

37. Landgraf JM, Abetz LN. Measuring health outcomes in pediatric populations: issues in psychometrics and application. In: Spilker B, ed. Quality of Life and Pharmacoeconomics in Clinical Trials. Philadelphia, Lippincott-Raven Publishers, 1996; pp. 793-802.

38. West A. Methodological issues in the assessment of quality of life in childhood asthma: what educational research has to offer. In: Christie M, French D, eds. Assessment of Quality of Life in Childhood Asthma. Chur, Harwood Academic Publishers, 1994; pp. 121-130.

39. McGee HM. Quality of life: assessment issues for children with chronic illness and their families. In: Christie M, French D, eds. Assessment of Quality of Life in Childhood Asthma. Chur, Harwood Academic Publishers, 1994; pp. 83-97.

40. Larson CO, Hays RD, Nelson EC. Do the pictures influence scores on the Dartmouth COOP Charts? Qual Life Res 1992; 1: 247-249.

41. Fowler FJ. Data collection methods. In: Spilker B, ed. Quality of Life and Pharmacoeconomics in Clinical Trials. Philadelphia, Lippincott-Raven Publishers, 1996; pp. 381-386.

42. Hibbert ME, Hamill C, Rosier M, Caust J, Patton G, Bowes G. Computer administration of a school-based adolescent health survey. J Paediatr Child Health 1996; 32: 372-377.

43. Landgraf JM, Abetz L, Ware JE. The child health questionnaire (CHQ): A user's manual. Boston, The Health Institute, New England Medical Center, 1996.

44. Streiner DL, Norman GR. Health Measurement Scales: A Practical Guide to Their Development and Use. Oxford, Oxford University Press, 1995; pp. 55-56.

45. Streiner DL, Norman GR. Health Measurement Scales: A Practical Guide to Their Development and Use. Oxford, Oxford University Press, 1995; pp. 4-14.

46. Kind P. Measuring quality of life in children. In: Christie M, French D, eds. Assessment of quality of life in childhood asthma. Chur, Harwood Academic Publishers, 1994; pp. 107-117.

47. Czyzewski DI, Mariotto MJ, Bartholomew LK, LeCompte $\mathrm{SH}$, Sockrider MM. Measurement of quality of well being in a child and adolescent cystic fibrosis population. Med Care 1994; 32: 965-972.

48. Lydick E, Epstein RS. Interpretation of quality of life changes. Qual Life Res 1993; 2: 221-226.

49. Jaeschke R, Singer J, Guyatt GH. Measurement of health status: ascertaining the minimal clinically important difference. Control Clin Trials 1989; 10: 407-415.

50. Deyo RA, Diehr P, Patrick DL. Reproducibility and responsiveness of health status measures: statistics and strategies for evaluation. Control Clin Trials 1991; 12: 142S$158 \mathrm{~S}$. 
51. National Health Interview Survey. Current estimates from the Health Interview Survey. NHIS Child Health Supplement, 1988.

52. Stein REK, Jones Jessop D. Functional status II(R): a measure of child health status. Med Care 1990; 28: 10411055.

53. Eisen M, Ware JE, Donald CA, Brook RH. Measuring components of children's health status. Med Care 1979; 17: 902-921.

54. Starfield B, Bergner M, Ensminger M, et al. Adolescent health status measurement: development of the child health and illness profile. Pediatrics 1993; 91: 430-435.

55. Starfield B, Riley AW, Green BF, et al. The adolescent child health and illness profile: a population-based measure of health. Med Care 1995; 33: 553-566.

56. Wasson JH, Kairys SW, Nelson EC, Kalishman N, Baribeau P. A short survey for assessing health and social problems of adolescents. J Fam Pract 1994; 38: 489-494.

57. Apajasalo M, Rautonen J, Holmberg C, et al. Quality of life in pre-adolescence: a 17-dimensional health-related measure (17D). Qual Life Res 1996; 5: 532-538.

58. Apajasalo M, Sintonen H, Holmberg C, et al. Quality of life in early adolescence: a sixteen-dimensional healthrelated measure (16D). Qual Life Res 1996; 5: 205-211.

59. Juniper EF, Guyatt GH, Epstein RS, Ferrie PJ, Jaeschke R, Hiller TK. Evaluation of impairment of health related quality of life in asthma: development of a questionnaire for use in clinical trials. Thorax 1992; 47: 76-83.

60. Boulet L-P, Boutin H, Côté J. Evaluation of an asthma self-management education program. J Asthma 1995; 32 : 199-206.

61. French DJ, Christie MJ, Sowden AJ. The reproducibility of the childhood asthma questionnaires: measures of quality of life for children with asthma aged 4-16 years. Qual Life Res 1994; 3: 215-224.

62. Christie MJ, French D, Sowden A, West A. Development of child-centered disease-specific questionnaires for living with asthma. Psychosom Med 1993; 55: 541-548.

63. Hewer SL, Hobbs J, French D, Lenney W. Pilgrim's progress: the effect of salmeterol in older children with chronic severe asthma. Respir Med 1995; 89: 435-440.

64. Creer TL, Wigal JK, Kotses H, Hatala JC, McConnaughy $\mathrm{K}$, Winder JA. A life activities questionnaire for childhood asthma. J Asthma 1993; 30: 467-473.

65. Usherwood TP, Scrimgeour A, Barber JH. Questionnaire to measure perceived symptoms and disability in asthma. Arch Dis Child 1990; 65: 779-781.

66. Rosier MJ, Bishop J, Nolan T, Robertson CF, Carlin JB, Phelan PD. Measurement of functional severity of asthma in children. Am J Respir Crit Care Med 1994; 149: 14341441.

67. Creer TL, Marion RJ, Creer PP. Asthma problem behavior checklist: parental perceptions of the behavior of asthmatic children. J Asthma 1983; 20: 97-104.

68. Schlösser M, Havermans G. A self-efficacy scale for children and adolescents with asthma: construction and validation. J Asthma 1992; 29: 99-108.

69. Townsend M, Feeny DH, Guyatt GH, Furlong WJ, Seip AE, Dolovich J. Evaluation of the burden of illness for pediatric asthmatic patients and their parents. Ann Allergy 1991; 67: 403-408.

70. Stein REK, Riessman CK. The development of an impact-on-family scale: preliminary findings. Med Care 1980; 18: 465-472.

71. Morris KP, ShaIp J, Watson S, Coulthard MG. Non-cardiac benefits of human recombinant erythroproietin in end stage renal failure and anaemia. Arch Dis Child 1993; 69: 580-586.

72. Bicho A, Damas L, De Lurdes Chieira M. Asthma in adolescence. Pediatr Asthma Allergy Immunol 1992; 6: 197-203. 